\title{
Endothelium-derived Relaxing Factors of Small Resistance Arteries in Hypertension
}

\author{
Kyu-Tae Kang ${ }^{1,2}$ \\ ${ }^{1}$ College of Pharmacy, Duksung Women's University, Seoul, Korea \\ ${ }^{2}$ Innovative Drug Center, Duksung Women's University, Seoul, Korea
}

(Received July 10, 2014; Revised August 27, 2014; Accepted September 15, 2014)

\begin{abstract}
Endothelium-derived relaxing factors (EDRFs), including nitric oxide (NO), prostacyclin $\left(\mathrm{PGI}_{2}\right)$, and endothelium-derived hyperpolarizing factor (EDHF), play pivotal roles in regulating vascular tone. Reduced EDRFs cause impaired endothelium-dependent vasorelaxation, or endothelial dysfunction. Impaired endothelium-dependent vasorelaxation in response to acetylcholine (ACh) is consistently observed in conduit vessels in human patients and experimental animal models of hypertension. Because small resistance arteries are known to produce more than one type of EDRF, the mechanism(s) mediating endothelium-dependent vasorelaxation in small resistance arteries may be different from that observed in conduit vessels under hypertensive conditions, where vasorelaxation is mainly dependent on NO. EDHF has been described as one of the principal mediators of endothelium-dependent vasorelaxation in small resistance arteries in normotensive animals. Furthermore, EDHF appears to become the predominant endothelium-dependent vasorelaxation pathway when the endothelial NO synthase (NOS3)/NO pathway is absent, as in NOS3-knockout mice, whereas some studies have shown that the EDHF pathway is dysfunctional in experimental models of hypertension. This article reviews our current knowledge regarding EDRFs in small arteries under normotensive and hypertensive conditions.
\end{abstract}

Key words: Endothelium-derived relaxing factors, Small resistance arteries, Hypertension

\section{ENDOTHELIUM-DERIVED RELAXING FACTORS (EDRFS)}

Vascular endothelial cells play pivotal roles in maintaining cardiovascular homeostasis. The endothelium provides not only a physical barrier between the vessel wall and lumen, but also performs a critical function for the maintenance of blood pressure by releasing vasorelaxing factors and vasocontracting factors. Evidence of EDRFs in regulating vascular reactivity was first suggested in the 1980s by Furchgott and Zawadzki (1), who reported that vascular relaxation by acetylcholine (ACh) required the presence of endothelial cells, and demonstrated that ACh stimulated endothelial cells to release EDRF to relax the underlying vascular smooth muscle. Today, it is well known that the

\footnotetext{
Correspondence to: Kyu-Tae Kang, College of Pharmacy, Duksung Women's University, Seoul 132-714, Korea

E-mail: ktkang@duksung.ac.kr
}

This is an Open-Access article distributed under the terms of the Creative Commons Attribution Non-Commercial License (http:// creativecommons.org/licenses/by-nc/3.0) which permits unrestricted non-commercial use, distribution, and reproduction in any medium, provided the original work is properly cited.
Table 1. Endothelium-derived relaxing factors (EDRFs) and endothelium-derived contracting factors (EDCFs) of small resistance arteries

\begin{tabular}{ll}
\hline \hline \multicolumn{1}{c}{ EDRFs } & \multicolumn{1}{c}{ EDCFs } \\
\hline Nitric oxide $(\mathrm{NO})$ & Endothelin-1 \\
Prostacyclin $\left(\mathrm{PGI}_{2}\right)$ & Angiotensin II \\
Endothelium-derived hyperpolarizing & Thromboxane $\mathrm{A}_{2}\left(\mathrm{TxA}_{2}\right)$ \\
$\quad$ factors (EDRFs): & Prostaglandin $\mathrm{H}_{2}$ \\
Potassium ion $\left(\mathrm{K}^{+}\right)$ & Reactive oxygen species \\
Myo-endothelial gap junctions & (ROS) \\
Epoxyeicosatrienoic acids (EETs) & \\
Hydrogen peroxide $\left(\mathrm{H}_{2} \mathrm{O}_{2}\right)$ & \\
\hline
\end{tabular}

stimulation of endothelial cells by neurotransmitters, hormones, substances derived from platelets, and mechanical shear stress causes the release of EDRFs and/or endothelium-derived contracting factors (EDCFs) according to cell conditions (Table 1) (2). Classically, the term EDRF referred mainly to NO; however, it has since been recognized that there are several types of EDRFs, including $\mathrm{NO}, \mathrm{PGI}_{2}$, and EDHF. Each EDRF induces the relaxation of proximal vascular smooth muscle cells through its own pathway (Fig. 
(A)

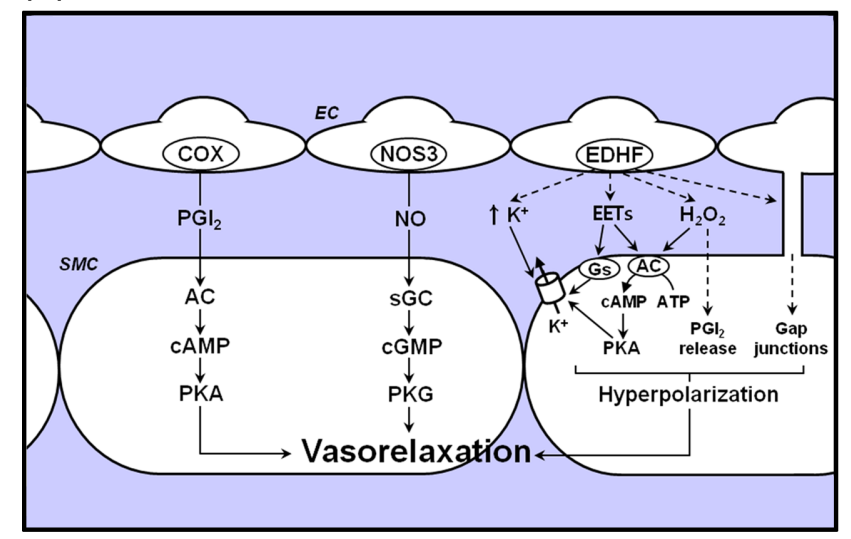

(B)

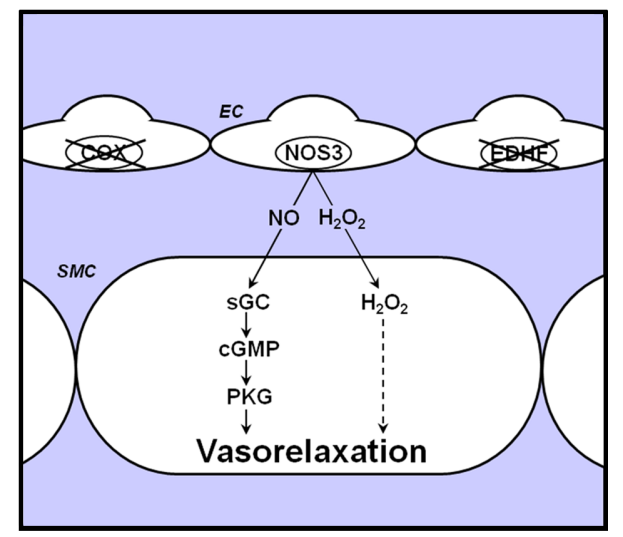

Fig. 1. Endothelium-derived relaxing factors of small resistance arteries in normotensive and hypertensive conditions. EC: endothelial cells, SMC: smooth muscle cells. (A) Small resistance arteries induce vasorelaxation via multiple vasorelaxing pathways including NOS, $\mathrm{COX}$, and EDHF pathways in the normotensive condition. COX in endothelial cells produces $\mathrm{PGI}_{2}$. $\mathrm{PGl}_{2}$ can cross the membrane of endothelial cells, and binds IP receptor on the plasma membrane of smooth muscle cells, which induces the activation of the adenylyl cyclase (AC)/cyclic adenosine monophosphate (CAMP)/protein kinase A (PKA) signal transduction pathway. Activated PKA phosphorylates target proteins, resulting in vasorelaxation. NOS3 produces NO in response to several stimuli such as shear stress, hypoxia, and vasoactive neurotransmitters. NO activates soluble guanylyl cyclase (sGC) in smooth muscle cells. Activated sGC catalyzes the conversion of guanosine triphosphate (GTP) to cyclic guanosine monophosphate (cGMP). cGMP directly and indirectly modulates numerous targets, including protein kinases such as protein kinase $\mathrm{G}(\mathrm{PKG})$, resulting in vasorelaxation. Intercellular $\mathrm{K}^{+}$ion, EETs, hydrogen peroxide $\left(\mathrm{H}_{2} \mathrm{O}_{2}\right)$, and gap junctions, proposed candidates of EDHF, induce various $\mathrm{K}^{+}$channels activation by complex mechanisms to facilitate hyperpolarization of the underlying smooth muscle cells, which results in vasorelaxation. (B) The NOS-dependent component becomes the primary EDRF pathway in small arteries in the hypertensive condition, in which NOS utilizes both NOS-derived NO/cGMP and NOS-dependent $\mathrm{H}_{2} \mathrm{O}_{2}$ to promote vasorelaxation, while other EDRFs are diminished.

1A). EDCFs include endothelin-1, angiotensin II, thromboxane $\mathrm{A}_{2}\left(\mathrm{TxA}_{2}\right)$, prostaglandin $\mathrm{H}_{2}$, and reactive oxygen species (ROS), all of which cause vascular contractions as well as various other functions (3). Thus, the endothelium can directly regulate vascular tone through the production and release of EDRFs and EDCFs.

Nitric oxide (NO). Seven years after presentation of the first evidence of EDRF by Furchgott and Zawadzki, the extraordinary discovery that EDRF was the freely diffusible gas NO was made (4). In 1992, NO was voted "molecule of the year" by Science, and in 1998 Robert F. Furchgott, Louis J. Ignarro, and Ferid Murad were honored with the Nobel Prize for their discoveries concerning "NO as a signaling molecule in the cardiovascular system."

$\mathrm{NO}$ is a diffusible and lipophilic-free radical with an in vivo half-life of less than 5 sec. NO is formed from L-arginine and molecular oxygen by NO synthase (NOS). NO serves several important roles in the vasculature. First, NO maintains vascular tone by relaxing vascular smooth muscle cells. NOS3-derived NO freely diffuses from the endothelial cells into the adjacent smooth muscle cells. The most well-recognized mechanism of NO for vasorelaxation is the activation of soluble guanylyl cyclase (sGC) in smooth muscle cells. Activated sGC catalyzes the conversion of guanosine triphosphate (GTP) to cyclic guanosine monophosphate
(cGMP). cGMP directly and indirectly modulates numerous targets, including protein kinases such as protein kinase G (PKG), phospholipase C (PLC), phosphodiesterases, tyrosine kinases, tyrosine phosphatases, and ion channels. PKG, the primary downstream target of cGMP in smooth muscle cells, activates the myosin light-chain phosphatase (MLCP), which dephosphorylates smooth muscle myosin. This process abrogates tonic contraction of the contractile apparatus, and results in vasorelaxation (5). Oelze et al. suggested that the phosphorylation of vasodilator-stimulated phosphoprotein (VASP) is a useful biochemical marker for monitoring the NO-stimulated cGMP/PKG pathway in vascular tissue (6). VASP was originally characterized as a substrate of both PKG and protein kinase A (PKA) (7). VASP belongs to the Ena/VASP family, and exists in numerous cell types including platelets, endothelial cells, smooth muscle cells and fibroblasts (8). Three VASP phosphorylation sites, Ser 157, Ser 239 and Thr 278, have been identified. Ser 239 is the major PKG-induced phosphorylation site, while Ser 157 is the major PKA-induced phosphorylation site (9). Several studies have demonstrated that VASP modulates vascular smooth muscle cell proliferation (10), but it appears not to have any functional roles in the cGMP- or cyclic adenosine monophosphate (cAMP)-induced relaxation of aortae from mice, although its phosphorylation is increased by cGMP or cAMP treatment (11). 
$\mathrm{NO}$ also has many other effects beyond vasorelaxation to maintain vascular homeostasis. NO inhibits smooth muscle cell proliferation, platelet aggregation, platelet and monocyte adhesion to the endothelium, low-density lipoprotein (LDL) oxidation, expression of adhesion molecules and endothelin-1 production (12).

Prostacyclin ( $\mathrm{PGI}_{2}$ : cyclooxygenase-derived metabolite). In addition to $\mathrm{NO}$, endothelial cells produce and release $\mathrm{PGI}_{2}$ in response to shear stress, hypoxia, and several other stimuli that also release $\mathrm{NO}$. $\mathrm{PGI}_{2}$ is lipid soluble and thus, after production in endothelial cells, it can cross the membranes of endothelial cells as a local vasorelaxing factor. $\mathrm{PGI}_{2}$ binds IP receptor on the plasma membrane of smooth muscle cells, which induces the activation of the adenylyl cyclase (AC)/cAMP/PKA signal transduction pathway. Activated PKA phosphorylates target proteins, resulting in vasorelaxation (13).

The rate limiting step of prostacyclin synthesis is the release of arachidonic acid from membrane-bound phospholipids by phospholipase $\mathrm{A}_{2}\left(\mathrm{PLA}_{2}\right)$, which is activated by increased intracellular $\mathrm{Ca}^{2+}(14)$. Arachidonic acid is metabolized by three major enzyme systems: lipoxygenase, epoxygenase (isoforms of cytochrome P450 (CYP)), and cyclooxygenase (COX). Lipoxygenase produces lipoxides, which are mainly vasoconstrictive. CYP products have important effects on vascular tone: epoxyeicosatrienoic acids (EETs) are candidates of EDHF as mentioned below, and hydroxyeicosatetraenoic acids (HETEs) exert vasoconstricting action (15). COX converts arachidonic acid to prostaglandin $\mathrm{H}_{2}$, which is further converted into several potential vasoactive prostanoids such as $\mathrm{PGI}_{2}$ and $\mathrm{TxA}_{2}$. Although $\mathrm{PGI}_{2}$ is the major prostanoid produced in endothelial cells, the balance between $\mathrm{PGI}_{2}$ and $\mathrm{TxA}_{2}$ production appears to be important for the regulation of vascular tone because $\mathrm{TxA}_{2}$ is vasocontractive in some vessels, unlike $\mathrm{PGI}_{2}$ (16).

\section{Endothelium-derived Hyperpolarizing Factor (EDHF).}

The existence of EDHF has been proposed based on observations that a substance released from the endothelium causes the hyperpolarization of vascular smooth muscle cells during NOS- and COX-independent relaxation in some small resistance vessel such as intramyocardial and small mesenteric arteries $(17,18)$. EDHF has been described as one of principal mediators of endothelium-dependent vasorelaxation in normotensive animals (19). The contribution of EDHF-mediated relaxation appears significantly greater in small resistance vessels than in large conduit vessels (20). Moreover, recent studies provided convincing evidence that EDHF appears to become the predominant endotheliumdependent vasorelaxation pathway when the endothelial NOS/NO pathway is absent, as demonstrated in NOS3knockout mice (21).

In resting conditions, the basal openings of the potassium ion $\left(\mathrm{K}^{+}\right)$channels result in resting membrane potentials around $-60 \mathrm{mV}$ in vascular smooth muscle cells, and low openings of voltage-gated $\mathrm{Ca}^{2+}$ channels provide a basal $\mathrm{Ca}^{2+}$ influx to establish resting basal vascular tone. Depolarization is caused by the inhibition of $\mathrm{K}^{+}$channels and activation of $\mathrm{Ca}^{2+}$ channels, which in turn causes vasoconstriction. If $\mathrm{K}^{+}$channels are stimulated to be opened by certain stimuli, $\mathrm{K}^{+}$ efflux occurs and causes hyperpolarization, which decreases the opening of voltage-gated $\mathrm{Ca}^{2+}$ channels to reduce $\mathrm{Ca}^{2+}$ influx, resulting in vascular relaxation (22). Because hyperpolarization is caused by the opening of $\mathrm{K}^{+}$channels, pharmacological inhibition of these channels has been applied to investigate EDHF-mediated responses. Indeed, EDHFmediated response is blocked by a combination of charybdotoxin, which blocks both large and intermediate conductance $\mathrm{Ca}^{2+}$-activated $\mathrm{K}^{+}$channels $\left(\mathrm{BK}_{\mathrm{Ca}}\right.$ and $\mathrm{IK}_{\mathrm{Ca}}$, respectively), and apamin, which blocks small conductance calcium-activated $\mathrm{K}^{+}$channels $\left(\mathrm{SK}_{\mathrm{Ca}}\right)$. However, these findings do not rule out the participation of other $\mathrm{K}^{+}$channels such as inward rectifier $\mathrm{K}^{+}$channel $\left(\mathrm{K}_{\mathrm{IR}}\right)$, voltage-gated $\mathrm{K}^{+}$channel $(\mathrm{Kv})$, ATP-sensitive $\mathrm{K}^{+}$channel $\left(\mathrm{K}_{\text {ATP }}\right)$ or $\mathrm{Na}^{+} / \mathrm{K}^{+}$-ATPase in EDHF-mediated responses.

Although it appears that EDHF is important to maintain normal vascular tone and resistance in small resistance arteries, the identity and exact role of EDHF in the pathogenesis of hypertension as well as under normal conditions are not completely understood. Such confusion may be attributed to the existence of more than one EDHF within a single vessel. Candidates proposed as EDHFs include $\mathrm{K}^{+}$ ion, gap junctions, EETs, and hydrogen peroxide $\left(\mathrm{H}_{2} \mathrm{O}_{2}\right)$ (23).

A small increase of $\mathrm{K}^{+}$ion $(1 \sim 15 \mathrm{mmol} / \mathrm{L})$ in the intercellular space between endothelial cells and smooth muscle cells can lead to hyperpolarization of vascular smooth muscle cells, thereby causing vasorelaxation (24). Edwards et al. observed that $\mathrm{ACh}$ increased intercellular $\mathrm{K}^{+}$concentrations, and that this finding was correlated with ACh-induced hyperpolarization of both endothelial and smooth muscle cells, resulting in vasorelaxation. $\mathrm{K}^{+}$-induced hyperpolarization is associated with the activation of $\mathrm{IK}_{\mathrm{Ca}}$ and $\mathrm{SK}_{\mathrm{Ca}}$ on endothelial cells, and $\mathrm{K}_{\mathrm{IR}}$ and $\mathrm{Na}^{+} / \mathrm{K}^{+}$pump on smooth muscle cells, suggesting that $\mathrm{K}^{+}$-induced hyperpolarization was initiated by the opening of various $\mathrm{K}^{+}$channels.

Myo-endothelial gap junctions connect endothelial cells and smooth muscle cells. Gap junctions resemble pores allowing the transfer of ions and polar molecules, thereby providing the transmission of hyperpolarization between cells. Gap junctions are formed by the docking of connexins presented on the adjacent cells. In many vessels, pharmacological blockade of gap junctions blunts EDHF-mediated responses $(25,26)$. Antibodies against connexin 40 also block EDHF-mediated response in the endothelial cells of rat small mesenteric arteries (27). Interestingly, in spontaneously hypertensive rats (SHR), the protein expressions of 
connexins in endothelial cells of the mesenteric arteries were altered compared to those in Wistar-Kyoto rats (WKY), suggesting that gap junction-mediated response may be dysfunctional under hypertensive condition (28).

Epoxyeicosatrienoic acids (EETs), metabolites of arachidonic acid produced by the epoxygenase (cytochrome P450, CYP) pathway, have been proposed as an important regulator of vascular tone, especially coronary, cerebral, and renal vascular beds $(29,30)$. Agonists such as ACh and bradykinin release 14,15-EET from endothelial cells (31). Exogenous 11,12- and 14,15-EETs induce vasorelaxation of bovine coronary arteries via activation of $\mathrm{BK}_{\mathrm{Ca}}(32,33)$. EETs activate $\mathrm{BK}_{\mathrm{Ca}}$ by several mechanisms. EETs-mediated $\mathrm{BK}_{\mathrm{Ca}}$ activation can be elicited through G-protein signaling pathway in coronary smooth muscle cells (34), the cAMP/PKA pathway in renal afferent arteries (35), or by Vanilloid transient receptor potential channel (TRPV4)mediated transient intracellular $\mathrm{Ca}^{2+}$ modulation in cerebral arteries (36). In human subcutaneous arteries, non-NO and non- $\mathrm{PGI}_{2}$-mediated relaxation by $\mathrm{ACh}$ is blocked by miconazole, which is a CYP inhibitor (37). EDHF-mediated relaxation and hyperpolarization are attenuated by the transfection of porcine coronary arteries with CYP 2C8/34 antisense oligonucleotides (30). Thus, EETs are synthesized in endothelial cells, and cause hyperpolarization of smooth muscle cells via the activation of $\mathrm{K}^{+}$channels.

$\underline{\mathrm{H}_{2} \mathrm{O}_{2}}$ has been reported to induce contractions and/or relaxation in vascular tissue, dependent on species, vascular bed, and experimental conditions. $\mathrm{H}_{2} \mathrm{O}_{2}$ has been shown to cause contractions in aorta, pulmonary artery, and superior mesenteric artery of the rat, the porcine pulmonary artery, and the canine basilar artery (38). $\mathrm{H}_{2} \mathrm{O}_{2}$ also mediates endothelium-dependent and -independent vasorelaxation in mouse, rat, and human mesenteric arteries and in porcine, canine and human coronary microvessels $(39,40)$. It has been proposed that $\mathrm{H}_{2} \mathrm{O}_{2}$ can act as a EDHF due to the observation that EDHF-mediated relaxation and hyperpolarization by ACh after the blockade of NOS and the COX pathway was prevented partially or totally by a catalase, $\mathrm{H}_{2} \mathrm{O}_{2}$ metabolizing enzyme, in small mesenteric arteries from mice (41). $\mathrm{H}_{2} \mathrm{O}_{2}$ has been reported to cause hyperpolarization by several mechanisms including the cGMP or cAMP-meditated pathway, activation of PKA/PLA 2 to release $\mathrm{PGI}_{2}$, or direct activation of various $\mathrm{K}^{+}$channels dependent on the vascular bed and species (39). Endothelial cells generate ROS in healthy conditions as well as pathophysiological conditions. There are several endothelial sources of ROS such as NOS3, COX, lipoxygenase, CYP, and nicotinamide adenine dinucleotide phosphate (NADPH) oxidases (42). In studies by Matoba et al., ACh-induced $\mathrm{H}_{2} \mathrm{O}_{2}$ production was markedly reduced in small mesenteric arteries from NOS3-knockout mice, suggesting that NOS3 is an endothelial source of $\mathrm{H}_{2} \mathrm{O}_{2}$ (41). However, other sources such as xanthine oxidase and NADPH oxidase may produce $\mathrm{H}_{2} \mathrm{O}_{2}$ because catalase-sensitive $\mathrm{H}_{2} \mathrm{O}_{2}$ production is observed in NOS3-knockout mice (41).

\section{ENDOTHELIAL DYSFUNCTION IN HYPERTENSION}

Endothelial dysfunction is normally characterized by impaired endothelium-dependent vasorelaxation in response to agonists such as ACh, bradykinin, or shear stress. Pathophysiological mechanisms leading to impaired vasorelaxation may be due to imbalances between endothelium-derived vasoactive factors, either a reduction of EDRFs or an enhancement of EDCFs. In particular, reduced production and/or bioavailability of NO is largely considered to be a central mechanism responsible for endothelial dysfunction, even though other EDRFs and/or EDCFs may be involved in the pathogenesis of endothelial dysfunction. Reduced NO production may occur be due to decreased NOS3 protein expression and/or reduced NOS3 activity. Recently, many studies have shown that NOS3 protein expression is unchanged or even increased in cardiovascular disease conditions such as angiotensin II-infused hypertensive rats (ANG) (43), deoxycorticosterone acetate-salt hypertensive rats (DOCA) (43), SHR (44), diabetic rats (45), and atherosclerotic apo E-deficient mice (46). Thus, reduced NO production may be caused by altered NOS3 activity rather than decreased NOS3 protein expression. Indeed, altered NOS3 enzymatic activity has been reported in many hypertension models, possibly due to mislocalization, uncoupling, and/or lower substrate availability (47). On the other hand, NO bioavailability can be reduced due to excessive scavenging by $\mathrm{O}_{2}^{-}$. Increased generation of $\mathrm{O}_{2}^{-}$occurs in oxidative stress conditions, and $\mathrm{O}_{2}^{-}$reacts with $\mathrm{NO}$ to form $\mathrm{ONOO}^{-}$, which itself can cause vasoconstriction and lead to NOS uncoupling, lipid peroxidation, and vascular damage.

Endothelial dysfunction has been implicated in numerous cardiovascular diseases, such as hypertension, coronary artery disease, chronic heart failure, peripheral artery disease, diabetes, and chronic renal failure. Endothelial dysfunction is also important in the pathogenesis of atherosclerosis because it contributes to the initiation and evolution of prothrombotic, proinflammatory, and proliferative states. Furthermore, many studies have reported endothelial dysfunction caused by drugs and toxic materials in the environment. For example, Cyclosporin A, an immunosuppressive agent, inhibits endothelium-dependent relaxation to ACh (48). Arsenite also suppresses ACh-induced vasorelaxation by inhibiting NOS activity (49).

Endothelial dysfunction in hypertension is a systemic phenomenon associated with impaired vasorelaxation, thereby contributing to the further increase of arterial blood pressure (50). Endothelial dysfunction has been observed in human patients with essential hypertension or renovascular hypertension (51). Vasorelaxation of the forearm and coronary blood flow in response to the intra-arterial injection of 
ACh were reduced, whereas response to exogenous nitrovasodilators such as sodium nitroprusside was not altered (52,53). Such impaired endothelium-dependent vasorelaxation has also been observed in numerous studies using hypertensive animal models.

Cause or consequence? Endothelial dysfunction can occur at an early stage of hypertension, and hence may make an important contribution to the increase of blood pressure. On the other hand, endothelial dysfunction is regarded to be a consequence of hypertension, and, in these conditions endothelial dysfunction may contribute to further increases in peripheral vascular resistance and cardiovascular complications of the disease process.

In $\mathrm{SHR}$, the vasorelaxation caused by $\mathrm{ACh}$ in the aorta and in perfused mesenteric resistance arteries is impaired in adults with high arterial blood pressure, but not in young animals $(54,55)$, suggesting that endothelial dysfunction is a consequence of the increased hemodynamic load and shear stress in the hypertensive condition rather than a cause of hypertension in genetic experimental animal models of hypertension. In addition, the ability to correct impaired endothelium-dependent relaxation by using the appropriate antihypertensive treatment $(56,57)$ supports the suggestion that endothelial dysfunction may be secondary to the exposure of chronic higher blood pressure, and that impaired endothelium-dependent relaxation does not play a primary role in the initiation of the hypertensive process (58). Indeed, antihypertensive treatment using a combination of reserpine, hydrochlorothiazide, and hydralazine reverses decreased endothelium-dependent relaxation in response to ACh in aortae from Dahl salt-sensitive hypertensive rats (56).

Sequential studies of endothelial dysfunction have rarely been done in hypertensive human patients, and available reports have demonstrated controversial results. ACh-mediated forearm vasodilation is reduced in normotensive subjects with familial histories of essential hypertension, suggesting that endothelium dysfunction can precede the appearance of hypertension and that this abnormality plays a role in the pathogenesis of essential hypertension (59).

Heterogeneity of endothelial dysfunction dependent on vessel size. Small arteries with diameters of 200 microns or less play a critical role in the regulation of peripheral vascular resistance. Thus, dysregulation of vascular tone in these arteries may contribute significantly to high blood pressure.

ACh-induced vasorelaxation is blunted in conduit vessels in genetic and experimental hypertensive rodent models such as SHR (60), DOCA (61), Dahl salt-sensitive hypertensive rats, renovascular hypertensive rats (62), and ANG (63). However, both unchanged and impaired ACh-induced vasorelaxation have been observed in small mesenteric arteries from DOCA $(64,65)$, SHR $(66,67)$, and ANG rats (68) and mice (69). These controversial results have also been observed in small arteries in human patients with essential and secondary hypertension (70-74). Therefore, although impaired endothelium-dependent relaxation is accepted as a general phenomenon in hypertension, certain vascular beds appear to be more protected and have different degrees of endothelial dysfunction than others. Several reasons may be advocated to explain this heterogeneity, including different EDRF existence, altered sensitivity of smooth muscle cells to EDRF, enhanced local vascular EDCF, age of subjects, and/or different degrees of endothelial dysfunction in different vascular beds (58).

As noted above, several EDRFs including $\mathrm{NO}, \mathrm{PGI}_{2}$, and EDHF contribute to ACh-induced endothelium-dependent vasorelaxation (75). Furthermore, EDHF appears to be more important in small resistance arteries than in large conduit arteries, and may play a crucial role in maintaining peripheral vascular resistance (76). Tomioka et al. demonstrated that EDHF-mediated vasorelaxation became more predominant as vessel size became smaller, whereas ACh-induced relaxation in the aorta was entirely mediated by NO (20). In a study of hypertensive rats, we observed a novel mechanism of the NOS pathway in small arteries distinct from large arteries under hypertensive conditions (77), indicating that the NOS-dependent component of ACh-induced vasorelaxation in small arteries from hypertensive rats is increased, and is mediated by NOS-derived NO/cGMP as well as NOS-dependent $\mathrm{H}_{2} \mathrm{O}_{2}$, while other EDRFs are diminished (Fig. 1B). This finding demonstrates that the NOS-mediated pathway becomes the primary EDRF pathway in small arteries in hypertensive conditions, in which NOS utilizes two mediators (both $\mathrm{NO}$ and $\mathrm{H}_{2} \mathrm{O}_{2}$ ) to promote vasorelaxation compared to normotensive condition.

\section{PERSPECTIVES}

Endothelium-dependent vasorelaxation in small resistance arteries may be different from that observed in conduit vessels in hypertensive conditions. Small resistance arteries are known to induce vasorelaxation via multiple vasorelaxing pathways including NOS, COX, and EDHF pathways in normotensive conditions. However, whether these vasorelaxing pathways in small arteries are altered or not in hypertensive conditions is still under investigation. We previously found that NOS-mediated pathway plays a predominant role in maintaining ACh-induced vasorelaxation to compensate for the dysfunctional EDHF pathway in small mesenteric arteries under hypertensive conditions (77). Furthermore, increased NOS-dependent pathways in the vasorelaxation of small arteries under hypertensive conditions is mediated by both NOS-derived NO/cGMP signaling and NOS-mediated $\mathrm{H}_{2} \mathrm{O}_{2}$. Further studies are necessary to determine the exact mechanism of NOS-dependent $\mathrm{H}_{2} \mathrm{O}_{2}$-mediated vasore- 
laxation in small mesenteric arteries under hypertensive conditions. An increased understanding of different vasorelaxing mechanisms in small arteries under hypertensive conditions will help clinicians to identify the proper target(s) to treat endothelial dysfunction in hypertensive patients.

\section{ACKNOWLEDGMENT}

This work was supported by the Duksung Women's University Research Grants of 2013 (3000002002).

\section{REFERENCES}

1. Furchgott, R.F. and Zawadzki, J.V. (1980) The obligatory role of endothelial cells in the relaxation of arterial smooth muscle by acetylcholine. Nature, 288, 373-376.

2. Vanhoutte, P.M. (1989) Endothelium and control of vascular function. State of the Art lecture. Hypertension, 13, 658-667.

3. Luscher, T.F. and Barton, M. (1997) Biology of the endothelium. Clin. Cardiol., 20, II-3-10.

4. Palmer, R.M., Ferrige, A.G. and Moncada, S. (1987) Nitric oxide release accounts for the biological activity of endothelium-derived relaxing factor. Nature, 327, 524-526.

5. Dudzinski, D.M., Igarashi, J., Greif, D. and Michel, T. (2006) The regulation and pharmacology of endothelial nitric oxide synthase. Annu. Rev. Pharmacol. Toxicol., 46, 235-276.

6. Oelze, M., Mollnau, H., Hoffmann, N., Warnholtz, A., Bodenschatz, M., Smolenski, A., Walter, U., Skatchkov, M., Meinertz, T. and Munzel, T. (2000) Vasodilator-stimulated phosphoprotein serine 239 phosphorylation as a sensitive monitor of defective nitric oxide/cGMP signaling and endothelial dysfunction. Circ. Res., 87, 999-1005.

7. Halbrugge, M., Friedrich, C., Eigenthaler, M., Schanzenbächer, P. and Walter, U. (1990) Stoichiometric and reversible phosphorylation of a $46-\mathrm{kDa}$ protein in human platelets in response to cGMP- and cAMP-elevating vasodilators. J. Biol. Chem., 265, 3088-3093.

8. Reinhard, M., Halbrügge, M., Scheer, U., Wiegand, C., Jockusch, B.M. and Walter, U. (1992) The 46/50 kDa phosphoprotein VASP purified from human platelets is a novel protein associated with actin filaments and focal contacts. EMBO J., 11, 2063-2070.

9. Smolenski, A., Bachmann, C., Reinhard, K., Hönig-Liedl, P., Jarchau, T., Hoschuetzky, H. and Walter, U. (1998) Analysis and regulation of vasodilator-stimulated phosphoprotein serine 239 phosphorylation in vitro and in intact cells using a phosphospecific monoclonal antibody. J. Biol. Chem., 273, 20029-20035.

10. Chen, L., Daum, G., Chitaley, K., Coats, S.A., Bowen-Pope, D.F., Eigenthaler, M., Thumati, N.R., Walter, U. and Clowes, A.W. (2004) Vasodilator-stimulated phosphoprotein regulates proliferation and growth inhibition by nitric oxide in vascular smooth muscle cells. Arterioscler. Thromb. Vasc. Biol., 24, 1403-1408.

11. Aszódi, A., Pfeifer, A., Ahmad, M., Glauner, M., Zhou, X.H., Ny, L., Andersson, K.E., Kehrel, B., Offermanns, S. and Fassler, R. (1999) The vasodilator-stimulated phosphoprotein (VASP) is involved in cGMP- and cAMP-mediated inhibition of agonist-induced platelet aggregation, but is dispensable for smooth muscle function. EMBO J., 18, 37-48.

12. Fleming, I. and Busse, R. (2003) Molecular mechanisms involved in the regulation of the endothelial nitric oxide synthase. Am. J. Physiol. Regul. Integr. Comp. Physiol., 284, R112.

13. Kukovetz, W.R., Holzmann, S., Wurm, A. and Pöch, G. (1979) Prostacyclin increases cAMP in coronary arteries. $J$. Cyclic Nucleotide Res., 5, 469-476.

14. Chang, J., Musser, J.H. and McGregor, H. (1987) Phospholipase A2: function and pharmacological regulation. Biochem. Pharmacol., 36, 2429-2436.

15. Imig, J.D., Zou, A.P., Stec, D.E., Harder, D.R., Falck, J.R. and Roman, R.J. (1996) Formation and actions of 20-hydroxyeicosatetraenoic acid in rat renal arterioles. Am. J. Physiol., 270, R217-227.

16. Bunting, S., Moncada, S. and Vane, J.R. (1983) The prostacyclin--thromboxane A2 balance: pathophysiological and therapeutic implications. Br. Med. Bull., 39, 271-276.

17. Vanhoutte, P.M. (1987) Vascular physiology: the end of the quest? Nature, 327, 459-460.

18. Chen, G., Suzuki, H. and Weston, A.H. (1988) Acetylcholine releases endothelium-derived hyperpolarizing factor and EDRF from rat blood vessels. Br. J. Pharmacol., 95, 11651174.

19. Félétou, M. and Vanhoutte, P.M. (2006) Endothelium-derived hyperpolarizing factor: where are we now? Arterioscler. Thromb. Vasc. Biol., 26, 1215-1225.

20. Tomioka, H., Hattori, Y., Fukao, M., Sato, A., Liu, M., Sakuma, I., Kitabatake, A. and Kanno, M. (1999) Relaxation in different-sized rat blood vessels mediated by endotheliumderived hyperpolarizing factor: importance of processes mediating precontractions. J. Vasc. Res., 36, 311-320.

21. Huang, A., Sun, D., Smith, C.J., Connetta, J.A., Shesely, E.G., Koller, A. and Kaley, G. (2000) In eNOS knockout mice skeletal muscle arteriolar dilation to acetylcholine is mediated by EDHF. Am. J. Physiol. Heart Circ. Physiol., 278, H762-768.

22. Jackson, W.F. (2000) Ion channels and vascular tone. Hypertension, 35, 173-178.

23. Vanhoutte, P.M. (2004) Endothelium-dependent hyperpolarizations: the history. Pharmacol. Res., 49, 503-508.

24. Edwards, G., Dora, K.A., Gardener, M.J., Garland, C.J. and Weston, A.H. (1998) $\mathrm{K}+$ is an endothelium-derived hyperpolarizing factor in rat arteries. Nature, 396, 269-272.

25. Taylor, H.J., Chaytor, A.T., Evans, W.H. and Griffith, T.M. (1998) Inhibition of the gap junctional component of endothelium-dependent relaxations in rabbit iliac artery by 18-alpha glycyrrhetinic acid. Br. J. Pharmacol., 125, 1-3.

26. Edwards, G., Félétou, M., Gardener, M.J., Thollon, C., Vanhoutte, P.M. and Weston, A.H. (1999) Role of gap junctions in the responses to EDHF in rat and guinea-pig small arteries. $B r$. J. Pharmacol., 128, 1788-1794.

27. Mather, S., Dora, K.A., Sandow, S.L., Winter, P. and Garland, C.J. (2005) Rapid endothelial cell-selective loading of connexin 40 antibody blocks endothelium-derived hyperpolarizing factor dilation in rat small mesenteric arteries. Circ. Res., 97, 399-407.

28. Kansui, Y., Fujii, K., Nakamura, K., Goto, K., Oniki, H., Abe, I., Shibata, Y. and Iida, M. (2004) Angiotensin II receptor 
blockade corrects altered expression of gap junctions in vascular endothelial cells from hypertensive rats. Am. J. Physiol. Heart Circ. Physiol., 287, H216-224.

29. Campbell, W.B. and Harder, D.R. (1999) Endotheliumderived hyperpolarizing factors and vascular cytochrome P450 metabolites of arachidonic acid in the regulation of tone. Circ. Res., 84, 484-488.

30. Fisslthaler, B., Popp, R., Kiss, L., Potente, M., Harder, D.R., Fleming, I. and Busse, R. (1999) Cytochrome P450 2C is an EDHF synthase in coronary arteries. Nature, 401, 493-497.

31. Nithipatikom, K., Pratt, P.F. and Campbell, W.B. (2000) Determination of EETs using microbore liquid chromatography with fluorescence detection. Am. J. Physiol. Heart Circ. Physiol., 279, H857-862.

32. Campbell, W.B., Falck, J.R. and Gauthier, K. (2001) Role of epoxyeicosatrienoic acids as endothelium-derived hyperpolarizing factor in bovine coronary arteries. Med. Sci. Monit., 7, 578-584.

33. Pratt, P.F., Li, P., Hillard, C.J., Kurian, J. and Campbell, W.B. (2001) Endothelium-independent, ouabain-sensitive relaxation of bovine coronary arteries by EETs. Am. J. Physiol. Heart Circ. Physiol., 280, H1113-1121.

34. Li, P.L. and Campbell, W.B. (1997) Epoxyeicosatrienoic acids activate $\mathrm{K}+$ channels in coronary smooth muscle through a guanine nucleotide binding protein. Circ. Res., 80, 877-884.

35. Imig, J.D., Inscho, E.W., Deichmann, P.C., Reddy, K.M. and Falck, J.R. (1999) Afferent arteriolar vasodilation to the sulfonimide analog of 11, 12-epoxyeicosatrienoic acid involves protein kinase A. Hypertension, 33, 408-413.

36. Earley, S., Heppner, T.J., Nelson, M.T. and Brayden, J.E. (2005) TRPV4 forms a novel Ca2+ signaling complex with ryanodine receptors and BKCa channels. Circ. Res., 97, 12701279.

37. Coats, P., Johnston, F., MacDonald, J., McMurray, J.J. and Hillier, C. (2001) Endothelium-derived hyperpolarizing factor: identification and mechanisms of action in human subcutaneous resistance arteries. Circulation, 103, 1702-1708.

38. Ardanaz, N. and Pagano, P.J. (2006) Hydrogen peroxide as a paracrine vascular mediator: regulation and signaling leading to dysfunction. Exp. Biol. Med. (Maywood), 231, 237-251.

39. Shimokawa, H. and Morikawa, K. (2005) Hydrogen peroxide is an endothelium-derived hyperpolarizing factor in animals and humans. J. Mol. Cell. Cardiol., 39, 725-732.

40. Gao, Y.J., Hirota, S., Zhang, D.W., Janssen, L.J. and Lee, R.M. (2003) Mechanisms of hydrogen-peroxide-induced biphasic response in rat mesenteric artery. Br. J. Pharmacol., 138, 1085-1092.

41. Matoba, T., Shimokawa, H., Nakashima, M., Hirakawa, Y., Mukai, Y., Hirano, K., Kanaide, H. and Takeshita, A. (2000) Hydrogen peroxide is an endothelium-derived hyperpolarizing factor in mice. J. Clin. Invest., 106, 1521-1530.

42. Katusic, Z.S. (1996) Superoxide anion and endothelial regulation of arterial tone. Free Radical Biol. Med., 20, 443-448.

43. Sullivan, J.C., Pollock, D.M. and Pollock, J.S. (2002) Altered nitric oxide synthase 3 distribution in mesenteric arteries of hypertensive rats. Hypertension, 39, 597-602.

44. Nava, E., Llinás, M.T., Gonzalez, J.D. and Salazar, F.J. (1996) Nitric oxide synthase activity in renal cortex and medulla of normotensive and spontaneously hypertensive rats. Am. J.
Hypertens., 9, 1236-1239.

45. Hink, U., Li, H., Mollnau, H., Oelze, M., Matheis, E., Hartmann, M., Skatchkov, M., Thaiss, F., Stahl, R.A., Warnholtz, A., Meinertz, T., Griendling, K., Harrison, D.G., Forstermann, U. and Munzel, T. (2001) Mechanisms underlying endothelial dysfunction in diabetes mellitus. Circ. Res., 88, E14-22.

46. Laursen, J.B., Somers, M., Kurz, S., McCann, L., Warnholtz, A., Freeman, B.A., Tarpey, M., Fukai, T. and Harrison, D.G. (2001) Endothelial regulation of vasomotion in apoE-deficient mice: implications for interactions between peroxynitrite and tetrahydrobiopterin. Circulation, 103, 1282-1288.

47. Forstermann, U. and Munzel, T. (2006) Endothelial nitric oxide synthase in vascular disease: from marvel to menace. Circulation, 113, 1708-1714.

48. Gallego, M.J., Lopez Farre, A., Riesco, A., Monton, M., Grandes, S.M., Barat, A., Hernando, L., Casado, S. and Caramelo, C.A. (1993) Blockade of endothelium-dependent responses in conscious rats by cyclosporin A: effect of $\mathrm{L}$-arginine. $\mathrm{Am}$. J. Physiol., 264, H708-714.

49. Lee, M.Y., Jung, B.I., Chung, S.M., Bae, O.N., Lee, J.Y., Park, J.D., Yang, J.S., Lee, H. and Chung, J.H. (2003) Arsenicinduced dysfunction in relaxation of blood vessels. Environ. Health Perspect., 111, 513-517.

50. Lüscher, T.F. (1994) The endothelium in hypertension: bystander, target or mediator? J. Hypertens. Suppl., 12, S105116.

51. Taddei, S., Virdis, A., Mattei, P. and Salvetti, A. (1993) Vasodilation to acetylcholine in primary and secondary forms of human hypertension. Hypertension, 21, 929-933.

52. Linder, L., Kiowski, W., Buhler, F.R. and Luscher, T.F. (1990) Indirect evidence for release of endothelium-derived relaxing factor in human forearm circulation in vivo. Blunted response in essential hypertension. Circulation, 81, 1762-1767.

53. Treasure, C.B., Klein, J.L., Vita, J.A., Manoukian, S.V., Renwick, G.H., Selwyn, A.P., Ganz, P. and Alexander, R.W. (1993) Hypertension and left ventricular hypertrophy are associated with impaired endothelium-mediated relaxation in human coronary resistance vessels. Circulation, 87, 86-93.

54. Hongo, K., Nakagomi, T., Kassell, N.F., Sasaki, T., Lehman, M., Vollmer, D.G., Tsukahara, T., Ogawa, H. and Torner, J. (1988) Effects of aging and hypertension on endotheliumdependent vascular relaxation in rat carotid artery. Stroke, 19, 892-897.

55. Dohi, Y., Thiel, M.A., Buhler, F.R. and Luscher, T.F. (1990) Activation of endothelial L-arginine pathway in resistance arteries. Effect of age and hypertension. Hypertension, 16, 170-179.

56. Lüscher, T.F., Vanhoutte, P.M. and Raij, L. (1987) Antihypertensive treatment normalizes decreased endothelium-dependent relaxations in rats with salt-induced hypertension. Hypertension, 9, III193-197.

57. Takase, H., Moreau, P., Küng, C.F., Nava, E. and Luscher, T.F. (1996) Antihypertensive therapy prevents endothelial dysfunction in chronic nitric oxide deficiency. Effect of verapamil and trandolapril. Hypertension, 27, 25-31.

58. Luscher, T.F., Dohi, Y. and Tschudi, M. (1992) Endotheliumdependent regulation of resistance arteries: alterations with aging and hypertension. J. Cardiovasc. Pharmacol., 19 Suppl 5, S34-42. 
59. Taddei, S., Virdis, A., Mattei, P., Arzilli, F. and Salvetti, A. (1992) Endothelium-dependent forearm vasodilation is reduced in normotensive subjects with familial history of hypertension. J. Cardiovasc. Pharmacol., 20 Suppl 12, S193-195.

60. Sim, M.K. and Singh, M. (1987) Decreased responsiveness of the aortae of hypertensive rats to acetylcholine, histamine and noradrenaline. Br. J. Pharmacol., 90, 147-150.

61. Somers, M.J., Mavromatis, K., Galis, Z.S. and Harrison, D.G. (2000) Vascular superoxide production and vasomotor function in hypertension induced by deoxycorticosterone acetatesalt. Circulation, 101, 1722-1728.

62. Bennett, M.A., Watt, P.A. and Thurston, H. (1993) Impaired endothelium-dependent relaxation in two-kidney, one clip Goldblatt hypertension: effect of vasoconstrictor prostanoids. J. Hypertens. Suppl., 11, S134-135.

63. Laursen, J.B., Rajagopalan, S., Galis, Z., Tarpey, M., Freeman, B.A. and Harrison, D.G. (1997) Role of superoxide in angiotensin II-induced but not catecholamine-induced hypertension. Circulation, 95, 588-593.

64. White, R.M., Rivera, C.O. and Davison, C.B. (1996) Differential contribution of endothelial function to vascular reactivity in conduit and resistance arteries from deoxycorticosteronesalt hypertensive rats. Hypertension, 27, 1245-1253.

65. Pu, Q., Touyz, R.M. and Schiffrin, E.L. (2002) Comparison of angiotensin-converting enzyme (ACE), neutral endopeptidase (NEP) and dual ACE/NEP inhibition on blood pressure and resistance arteries of deoxycorticosterone acetate-salt hypertensive rats. J. Hypertens., 20, 899-907.

66. Li, J. and Bukoski, R.D. (1993) Endothelium-dependent relaxation of hypertensive resistance arteries is not impaired under all conditions. Circ. Res., 72, 290-296.

67. Fujii, K., Tominaga, M., Ohmori, S., Kobayashi, K., Koga, T., Takata, Y. and Fujishima, M. (1992) Decreased endotheliumdependent hyperpolarization to acetylcholine in smooth muscle of the mesenteric artery of spontaneously hypertensive rats. Circ. Res., 70, 660-669.

68. Virdis, A., Neves, M.F., Amiri, F., Viel, E., Touyz, R.M. and Schiffrin, E.L. (2002) Spironolactone improves angiotensin- induced vascular changes and oxidative stress. Hypertension, 40, 504-510.

69. Wang, D., Chabrashvili, T., Borrego, L., Aslam, S. and Umans, J.G. (2006) Angiotensin II infusion alters vascular function in mouse resistance vessels: roles of $\mathrm{O}$ and endothelium. J. Vasc. Res., 43, 109-119.

70. Deng, L.Y., Li, J.S. and Schiffrin, E.L. (1995) Endotheliumdependent relaxation of small arteries from essential hypertensive patients: mechanisms and comparison with normotensive subjects and with responses of vessels from spontaneously hypertensive rats. Clin. Sci. (Lond), 88, 611-622.

71. Rizzoni, D., Porteri, E., Castellano, M., Bettoni, G., Muiesan, M.L., Muiesan, P., Giulini, S.M. and Agabiti-Rosei, E. (1996) Vascular hypertrophy and remodeling in secondary hypertension. Hypertension, 28, 785-790.

72. Cockcroft, J.R., Chowienczyk, P.J., Benjamin, N. and Ritter, J.M. (1994) Preserved endothelium-dependent vasodilatation in patients with essential hypertension. N. Engl. J. Med., 330, 1036-1040.

73. Bruning, T.A., Chang, P.C., Hendriks, M.G., Vermeij, P., Pfaffendorf, M. and van Zwieten, P.A. (1995) In vivo characterization of muscarinic receptor subtypes that mediate vasodilatation in patients with essential hypertension. Hypertension, 26, 70-77.

74. Thybo, N.K., Mulvany, M.J., Jastrup, B., Nielsen, H. and Aalkjaer, C. (1996) Some pharmacological and elastic characteristics of isolated subcutaneous small arteries from patients with essential hypertension. J. Hypertens., 14, 993-998.

75. Furchgott, R.F. and Vanhoutte, P.M. (1989) Endotheliumderived relaxing and contracting factors. FASEB J., 3, 20072018.

76. Garland, C.J., Plane, F., Kemp, B.K. and Cocks, T.M. (1995) Endothelium-dependent hyperpolarization: a role in the control of vascular tone. Trends Pharmacol. Sci., 16, 23-30.

77. Kang, K.T., Sullivan, J.C., Sasser, J.M., Imig, J.D. and Pollock, J.S. (2007) Novel nitric oxide synthase--dependent mechanism of vasorelaxation in small arteries from hypertensive rats. Hypertension, 49, 893-901. 